\title{
- EFEITO DO TRICLOSAN NO PROCESSO FIBROSANTE DE CÉLULAS HEPÁTICAS LX-2 MEDIANTE A AÇÃO NA SÍNTESE DE ÁCIDO GRAXO DE NOVO
}

\author{
Juliana Fabiani Miranda ${ }^{1}$ \\ Brenda Oliveira da Silva ${ }^{2}$ \\ Letícia Ferreira Ramos ${ }^{3}$ \\ Letícia Rocha Gonçalves ${ }^{4}$ \\ Karen Cristiane Martinez de Moraes $^{5}$
}

\begin{abstract}
Resumo: A fibrose hepática é uma condição clínica presente na maioria das doenças hepáticas, caracterizada pelo aumento na sintese dos componentes da matriz extracelular na tentativa de cicatrização do tecido lesionado. A principal célula responsável pelo desenvolvimento da fibrose hepática é a célula estrelada hepática, localizada no espaço de Disse. Esta apresenta dois fenótipos: o quiescente e o ativado. O metabolismo de lipídeo na célula estrelada está relacionado com o fornecimento de energia para a iniciação e perpetuação do seu estado ativado. Dentro deste contexto a ácido graxo sintase (FASN), proteína chave da síntese de ácido graxo de novo torna-se alvo do estudo, uma vez que o metabolismo de lipídeos está intimamente relacionado ao processo fibrosante em células estreladas hepáticas. Sabe-se que o fármaco triclosan (TCS) é inibidor da proteína FASN na síntese de ácido graxo de novo, com potencial alteração do processo fibrosante em células estreladas hepáticas. Sendo assim, avaliamos os aspectos celulares e moleculares do efeito do fármaco TCS na modulação do metabolismo de lipídeo através da inibição da FASN em modelo de células estreladas hepáticas $L X-2$. Os resultados demonstraram que o TCS na concentração $50 \mu \mathrm{M}$ em cultura celular LX-2 crescida em $10 \%$ de soro bovino fetal (SBF) - estado ativado- promove alterações morfofuncionais nas células; tanto pela despolimerização dos filamentos de actina quanto pela formação de estruturas globulares de actina no citoesqueleto celular. Desta maneira, o fármaco TCS apresentou características possivelmente citotóxicas em células $L X-2 \mathrm{com} 10 \%$ de SBF. Por outro lado, o estudo da inibição da proteína FASN demonstrou resultados que sugerem uma transdiferenciação celular correlacionada com a reversão do quadro pró-fibrosante hepático em células $L X$ 2, com o aumento das gotículas de lipídeo no citoplasma e aumento da expressão dos genes relacionados ao metabolismo de lipídeos. Estes resultados requerem maiores investigações da modulação do fármaco TCS na patogenia investigada.

Palavras-chave: Fibrose hepática; LX-2; Metabolismo de lipídeo; Triclosan; FASN.
\end{abstract}

\footnotetext{
1 Ciências Biológicas/Universidade Estadual Paulista “Júlio de Mesquita Filho” (UNESP), Brasil. Email: miranda.julianaf@gmail.com.

2 Universidade Federal de Ouro Preto (NUPEB), Brasil. Email: brendabiologa@yahoo.com.br.

3 Ciências Biológicas/Universidade Estadual Paulista “Júlio de Mesquita Filho” (UNESP), Brasil. Email: leticiafraamos@hotmail.com.

4 Ciências Biológicas/Universidade Estadual Paulista “Júlio de Mesquita Filho" (UNESP), Brasil. Email: leticiarochagon@outlook.com

5 Ciências Biológicas/Universidade Estadual Paulista “Júlio de Mesquita Filho" (UNESP), Brasil. Email: karenmoraes_33@hotmail.com.
} 